\title{
A Method for the Production of Titanium-Tantalum Binary Alloys Using the Metalysis-FFC Process
}

\author{
Robert J. Howell ${ }^{1}$, Luke A. Benson Marshall ${ }^{2}$, Martin Jackson ${ }^{1}$, Brad P. Wynne ${ }^{1}$ \\ 1: The University of Sheffield, Department of Materials Science and Engineering, Mappin street, \\ Sheffield, S1 3JD,UK \\ 2: Metalysis Ltd., Materials Discovery Centre, Unit 4 R-Evolution@The AMP, Brindley Way, \\ Catcliffe, Rotherham, S60 5FS
}

\begin{abstract}
$\underline{\text { Abstract }}$
Titanium-tantalum alloys have historically been difficult to produce using conventional techniques due to the large difference in melting point and poor interdiffusivity rates of the two elements, leading to large levels of segregation. In this work we have investigated using the Metalysis-FFC process to overcome this problem. The Metalysis-FFC process is an electrochemical process where metal oxides are reduced by acting as a cathode in an electrolytic cell combined typically with a graphite anode and molten calcium chloride electrolyte. Previous work has proven that the process works when applied to mixed oxides to produce alloys. The reduction process is performed in the solid state and so negates the problems associated with traditional melting practices such as segregation and evaporation losses. In this work we have been able to successfully produce a range of Ti-Ta alloy powders from pure titanium to pure tantalum in $10 \mathrm{wt} \%$ increments using the Metalysis-FFC process. Moreover, energy dispersive spectroscopy analysis of the powders suggests uniform distribution of titanium and tantalum within all compositional ranges, suggesting the Metalysis-FFC process has the potential to be a transformative manufacturing methodology for producing titanium-tantalum alloys.
\end{abstract}

\section{$\underline{\text { Introduction }}$}

Tantalum possesses a range of properties that make it desirable for use as a refractory metal such as a high melting point $\left(3017{ }^{\circ} \mathrm{C}\right)$, good ductility and chemical inertness. However, the major use of tantalum is currently in the electronics industry as a material for capacitors. It is also used in small quantities as an alloying addition in specialist alloys. The unique properties of tantalum as a bulk material are yet to be fully exploited; this is in part due to the cost of extraction from its ore and the difficulty of alloying due to its high melting point. 
Another disadvantage of tantalum is its high density $\left(16.7 \mathrm{~g} . \mathrm{cm}^{-3}\right)$; a way to overcome this is to alloy it with a lightweight material such as titanium. Titanium-tantalum alloys have historically been difficult to conventionally produce due to the large difference in melting point and poor interdiffusivity rates of the two elements; leading to large levels of segregation [2, 3]. The phase diagram of the titanium-tantalum system shows full solubility of the two metals with two distinct phases (Figure 1); it should therefore be possible to produce alloys with an even distribution of both elements.

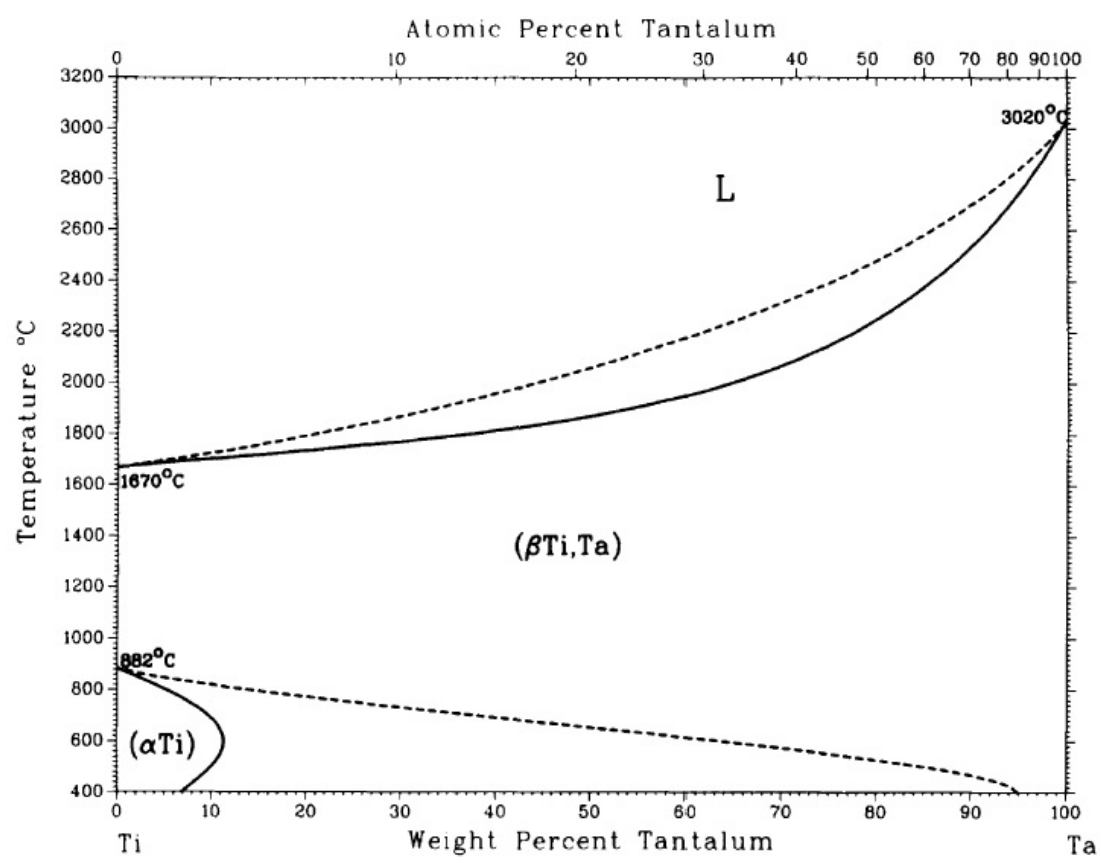

Figure 1 Phase Diagram of the Titanium-Tantalum System [1]

The aim of this study is to explore the production of tantalum and titanium-tantalum alloys via the direct electrochemical reduction of tantalum pentoxide by utilising the Metalysis-FFC process. This eliminates the need for a fluorotantalate intermediate and subsequent sodiothermic reduction; making it cleaner, greener and more cost effective. The FFC process, named after its founders - Fray, Farthing and Chen - who first observed it in ca.1997 at the University of Cambridge. They outlined a method for the electrochemical reduction of metal oxides contained within a molten salt electrolyte (typically $\mathrm{CaCl}_{2}$ ). This process has since been proven to be a viable method for producing a range of metal powders (e.g. cerium, aluminium-scandium and chromium) at temperatures well below their respective melting points and as such promises to reduces the energy consumption and production costs associated with primary metal extraction [4-6]. Powder technology company, Metalysis, have 
since developed the process enabling production on a larger scale and the rapid investigation of unique alloys.

The Metalysis-FFC process works by forming an electrolytic cell within the molten salt electrolyte in which the cathode is a metal oxide of choice, the anode can be inert or consumable (graphite). When a potential is applied above the reduction potential of the metal oxide, it is possible for reduction to occur. This occurs via the ionisation of oxygen within the metal oxide, shown in Equation 1:

$$
M O_{x}+n 2 e^{-} \rightarrow M O_{x-n}+n O^{2-}
$$

The oxygen anions then migrate towards the anode where they either react with it (carbon anode) to produce carbon/oxygen species ( $\mathrm{CO}_{\mathrm{x}}$, Equation 2) or combine with other oxygen anions (inert anode) to produce oxygen gas (Equation 3):

$$
\begin{gathered}
x O^{2-}+C \rightarrow \mathrm{CO}_{x}+x 2 e^{-} \\
O^{2-}+\mathrm{O}^{2-} \rightarrow \mathrm{O}_{2}+4 e^{-}
\end{gathered}
$$

The Metalysis-FFC process has proven to be an effective method for the production of tantalum from tantalum pentoxide [7]. Investigations have taken place to help understand the mechanism for reduction of $\mathrm{Ta}_{2} \mathrm{O}_{5}$ in $\mathrm{CaCl}_{2}-\mathrm{NaCl}$ under a voltage of $2.8 \mathrm{~V}$ at $1123 \mathrm{~K} \mathrm{[8].} \mathrm{This} \mathrm{investigation} \mathrm{found}$ that $\mathrm{Ta}_{2} \mathrm{O}_{5}$ went through several intermediate stages before completely reducing to Ta metal. The intermediates include: $\mathrm{Ta}_{2} \mathrm{O}_{5} \cdot 0.5 \mathrm{CaO}, \mathrm{Ta}_{2} \mathrm{O}_{5} \cdot 2 \mathrm{CaO}, \mathrm{Ta}_{2} \mathrm{O}_{5} \cdot 4 \mathrm{CaO}$. An interesting finding from this research was that the concentration of $\mathrm{CaO}$ in the melt affected the particle size of the Ta product.

It is possible to produce titanium via the Metalysis-FFC process by reducing $\mathrm{TiO}_{2}$ much in the same way that tantalum is produced from $\mathrm{Ta}_{2} \mathrm{O}_{5}$. A lot of work has been put into investigating the mechanistic pathway of the reduction during electrolysis in molten $\mathrm{CaCl}_{2}$ salt [9-11]. The process sees $\mathrm{TiO}_{2}$ go through several intermediate stages before it is fully reduced to Ti; these stages are outlined below in equations 4-10.

$$
\begin{aligned}
& 5 \mathrm{TiO}_{2}+\mathrm{Ca}^{2+}+2 e^{-} \rightarrow \mathrm{Ti}_{4} \mathrm{O}_{7}+\mathrm{CaTiO}_{3} \\
& 4 \mathrm{Ti}_{4} \mathrm{O}_{7}+\mathrm{Ca}^{2+}+2 e^{-} \rightarrow 5 \mathrm{Ti}_{3} \mathrm{O}_{5}+\mathrm{CaTiO}_{3} \\
& 3 \mathrm{Ti}_{3} \mathrm{O}_{5}+\mathrm{Ca}^{2+}+2 e^{-} \rightarrow 4 \mathrm{Ti}_{2} \mathrm{O}_{3}+\mathrm{CaTiO}_{3} \\
& 2 \mathrm{Ti}_{2} \mathrm{O}_{3}+\mathrm{Ca}^{2+}+2 e^{-} \rightarrow 3 \mathrm{TiO}+\mathrm{CaTiO}_{3}
\end{aligned}
$$




$$
\begin{gathered}
\mathrm{CaTiO}_{3}+\mathrm{TiO} \rightarrow \mathrm{CaTi}_{2} \mathrm{O}_{4} \\
\mathrm{CaTi}_{2} \mathrm{O}_{4}+2 e^{-} \rightarrow 2 \mathrm{TiO}+\mathrm{Ca}^{2+}+2 \mathrm{O}^{2-} \\
\mathrm{TiO}+2(1-\delta) e^{-} \rightarrow \mathrm{Ti}[\mathrm{O}] \delta+(1-\delta) \mathrm{O}^{2-}
\end{gathered}
$$

In this work, we aim to produce a range of titanium-tantalum alloys from pure titanium to pure tantalum in 10 wt\% increments, using the Metalysis-FFC process. $\mathrm{TiO}_{2}$ and $\mathrm{Ta}_{2} \mathrm{O}_{5}$ powders were mixed prior to electrolysis in different ratios in order to achieve the desired alloy upon reduction. The aim is to prove that this is a more cost effective and environmentally friendlier way of producing Ti-Ta alloys, opening them up to wider markets. Due to the unique properties of titanium and tantalum, we expect the resulting alloys to have good strength with high temperature stability with possible applications in fusion reactor materials or other high temperature heat exchangers.

\section{Experimental Methods}

\section{Oxide Characterisation}

The starting materials $\left(\mathrm{TiO}_{2}\right.$ and $\left.\mathrm{Ta}_{2} \mathrm{O}_{5}\right)$ were analysed by inductively coupled plasma mass spectrometry (ICP-MS), SEM, PSD

\section{Oxide Powder Mixing}

Prior to electrolysis $\mathrm{Ta}_{2} \mathrm{O}_{5}$ and $\mathrm{TiO}_{2}$ were mixed in the desired ratios (Table 1) along with water (40 $\mathrm{wt} \%$ ) and polyvinyl alcohol (PVA, $2.5 \mathrm{wt} \%$ ) to act as a binder in $100 \mathrm{~mL}$ plastic bottles. Samples were then subsequently mixed in a shaker-mixer (Turbula ${ }^{\circledR}$ T $10 \mathrm{~B}$ ) for 16 hours followed by drying at $80{ }^{\circ} \mathrm{C}$ for 16 hours. The resulting solid was then crushed using a pestle and mortar and sieved to achieve a particle size of 106-315 $\mu \mathrm{m}$ to produce an angular powder. The binder was then removed by heating the powder at $550{ }^{\circ} \mathrm{C}$ for two hours in air.

\section{Table 1 Mass of oxides used to produce desired alloy compositions}




\begin{tabular}{ccc}
\hline $\begin{array}{c}\text { For alloy } \\
\text { composition (wt } \%)\end{array}$ & TiO$_{2}$ mass $/ \mathbf{g}$ & Ta2 $\mathbf{O}_{5}$ mass / g \\
\hline Ti-10Ta & 46.2 & 3.8 \\
Ti-20Ta & 42.3 & 7.8 \\
Ti-30Ta & 38.1 & 11.9 \\
Ti-40Ta & 33.6 & 16.4 \\
Ti-50Ta & 28.9 & 21.1 \\
Ti-60Ta & 23.8 & 26.2 \\
Ti-70Ta & 18.5 & 31.5 \\
Ti-80Ta & 12.7 & 37.3 \\
Ti-90Ta & 6.6 & 43.4 \\
\hline
\end{tabular}

\section{Electrolysis}

Electrolysis of metal oxides was undertaken on a small scale $(\sim 25 \mathrm{~g})$ using a research and development cell at Metalysis Ltd. The cell consists of a sealed stainless steel retort contained within a furnace. A ceramic crucible containing dry $\mathrm{CaCl}_{2}(1.6 \mathrm{~kg})$ was placed into the retort to act as the electrolyte for the reduction. The metal oxide powder was contained within stainless steel baskets with a fine stainless steel gauze lining, this assembly acts as the cathode in the process. Cylindrical graphite anodes were used (outer diameter $=75 \mathrm{~mm}$, inner diameter $=25 \mathrm{~mm}$ ) and attached using two stainless steel current collectors. The current collectors from the anode and cathode were fed through seals in the retort head so that they could be easily raised and lowered in to the electrolyte.

During electrolysis the furnace was held at $950^{\circ} \mathrm{C}$ to ensure the $\mathrm{CaCl}_{2}$ electrolyte was molten and that the reduction could occur, the temperature was monitored using a thermocouple, which was also placed through a seal in the retort head. The reaction vessel was held under an inert atmosphere of argon, the outflow of which was monitored by mass spectrometry.

Reductions were performed by applying a constant current (5A) with an average voltage of approximately $3.5 \mathrm{~V}$ between the anode and cathode. An initial ramp-up of current $(0.5 \mathrm{~A} / \mathrm{min})$ was used to avoid excessive voltages and the production of $\mathrm{Cl}_{2}$. Reductions were run for 16 hours after the initial ramp-up, after which the potential was removed and the anode and cathode were raised out of the electrolyte and allowed to cool while still under a flow of argon. 


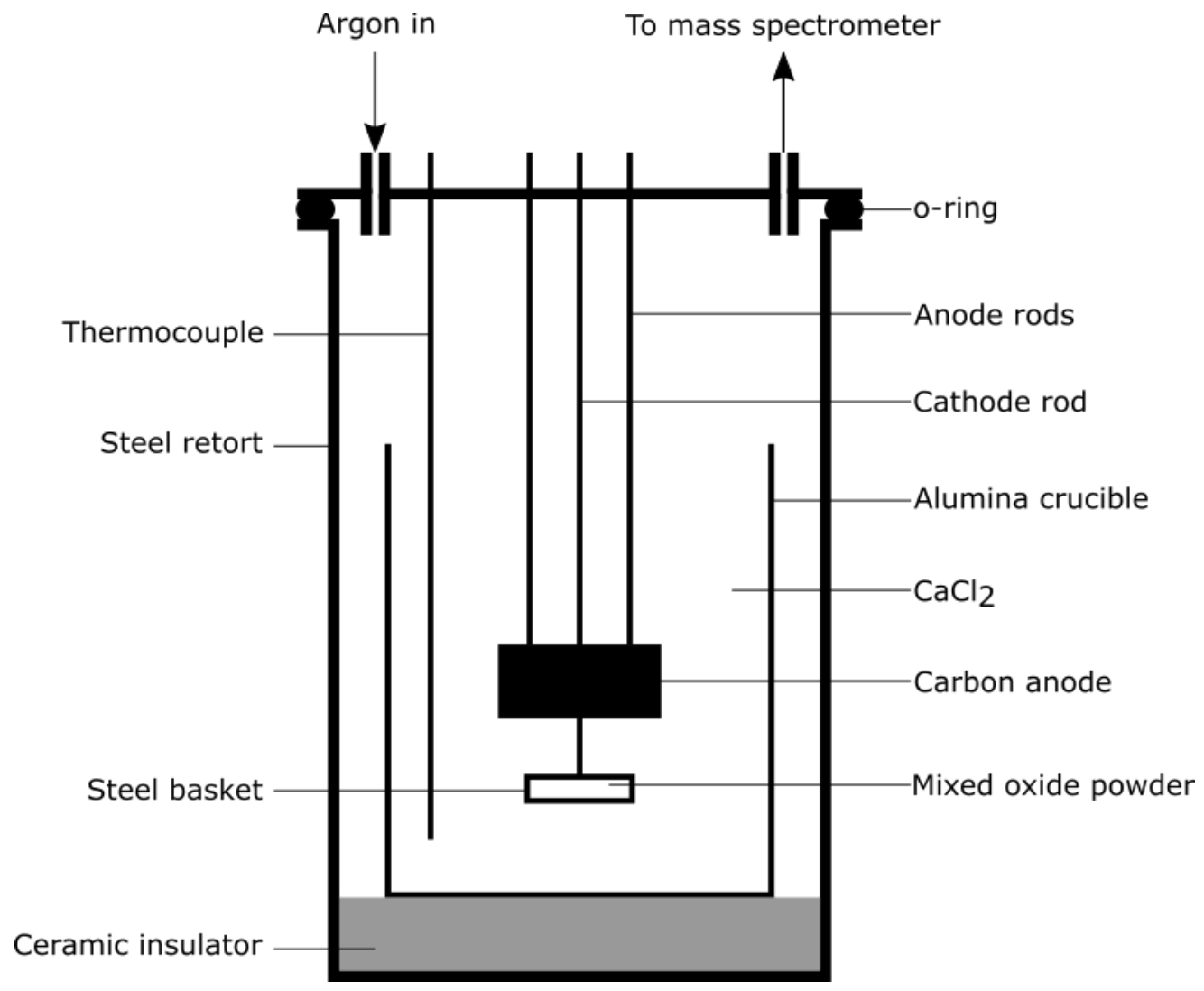

Figure 2 Schematic of R\&D electrolytic cell

\section{Post Processing}

Once cool, the reduced powder was removed and washed in hot water $\left(90^{\circ} \mathrm{C}, 200 \mathrm{~mL}\right)$ and left to cool for 30 minutes, which was then repeated. Powder samples were removed from their respective baskets and ground with a pestle and mortar. The metal powders were then dried in an oven $\left(40^{\circ} \mathrm{C}\right)$ for 16 hours.

\section{$X$-ray Diffraction (XRD)}

X-ray diffraction analysis was performed using a Bruker D2 Phaser x-ray diffractometer, Cu x-ray source (average wavelength $=1.54184 \AA$ ). Samples were scanned in the range $10-80^{\circ}$. Phase analysis was performed using the International Centre for Diffraction Data (ICDD) database 
Scanning Electron Microscopy (SEM)/Energy Dispersive Spectroscopy (EDS)

Samples were mounted in Bakelite and ground and polished to reveal a cross section of the metal powders. They were imaged under both backscattered and secondary electron detection using a scanning electron microscope (JEOL-JSM6490LV) at an acceleration voltage of $20 \mathrm{keV}$. Energy dispersive X-Ray spectroscopy (EDS) built in to the SEM instrument was used to analyse the chemical composition of samples.

\section{Oxygen/Nitrogen}

Oxygen and Nitrogen concentrations were measured by gas fusion analysis (Eltra ON-900, and Eltra CS-800).

\section{$\underline{\text { Results and Discussion }}$}

After electrolysis and post processing, the Ti-Ta metal powders were of irregular shape as shown by the SEM images (Figures $3 \mathrm{a}$ ai). There was a certain amount of intra granular closed porosity present as shown in the Figures. There was also the presence of some inter-granular porosity as shown in Figure 4; this could be due to the vacating of oxygen atoms from the particle and the subsequent contraction. 

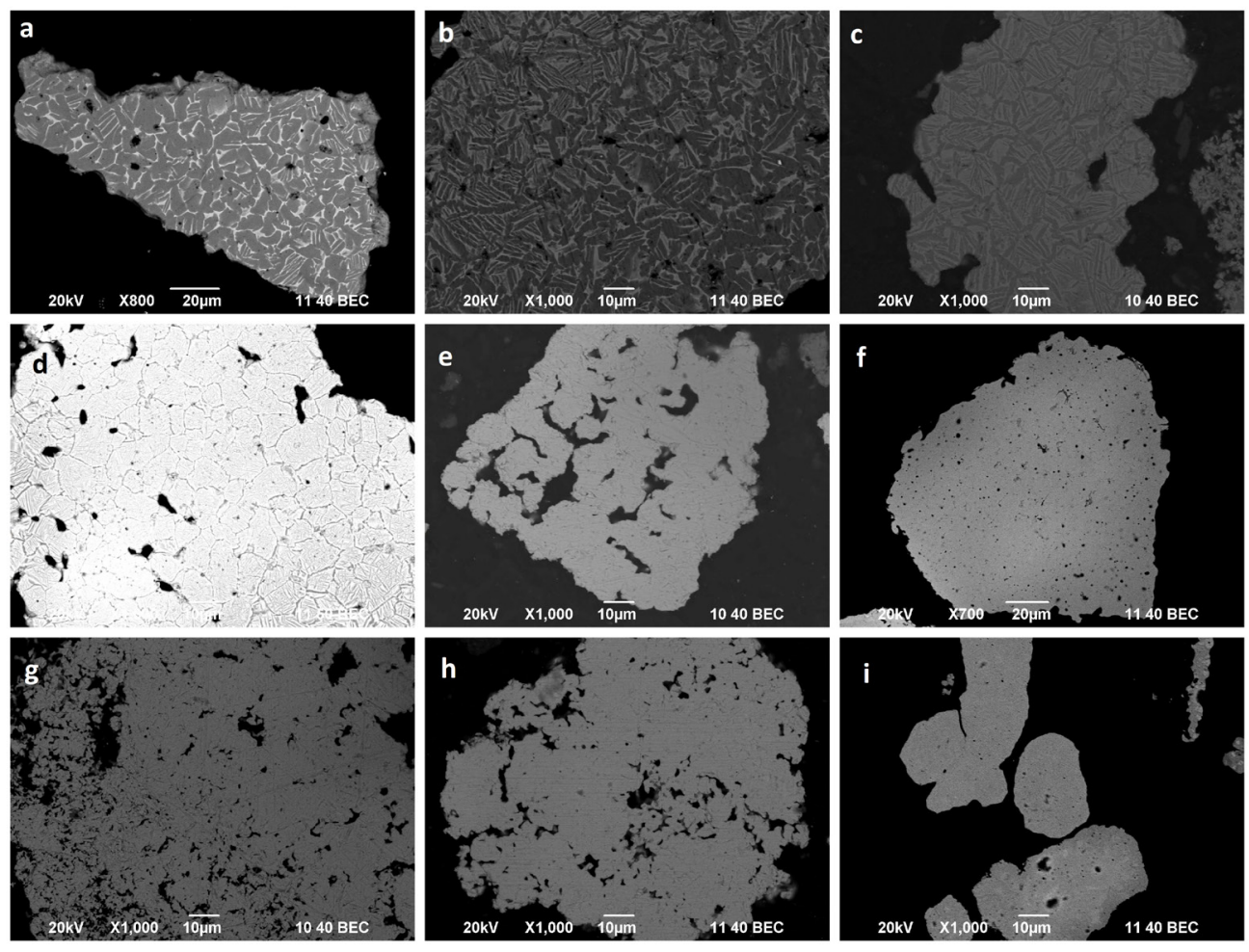

Figure 3 SEM (backscattered) images of Ti-Ta alloy powders: a) Ti-10Ta, b) Ti-20Ta, c) Ti-30Ta, d) Ti-40Ta, e) Ti -50Ta, f) Ti-60Ta, g) Ti-70Ta, h) Ti-80Ta, i) Ti-90Ta 


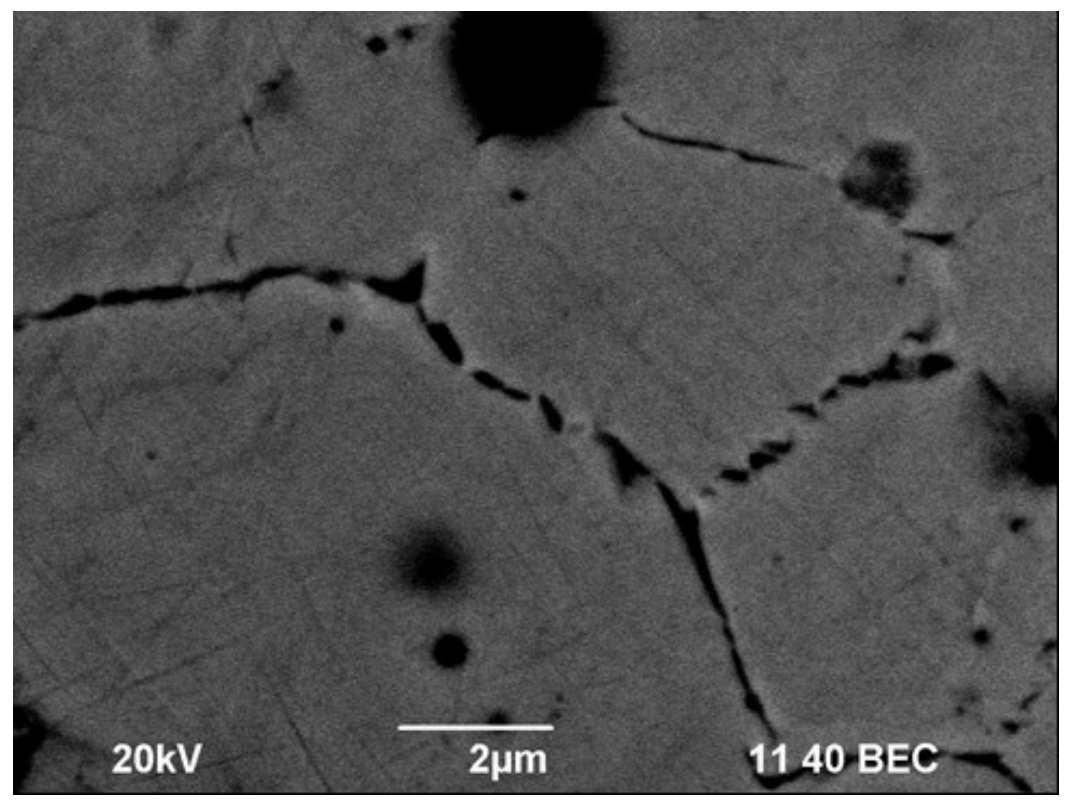

Figure 4 SEM (backscattered) image of a Ti-60Ta alloy particle exhibiting inter-granular porosity

Analysis by SEM (backscattered electron) shows a two-phase microstructure which is typical of an $\alpha+\beta$ titanium alloy and is in agreement with the phase diagram published in the literature [1]. With an operating temperature of $950^{\circ} \mathrm{C}$ it is presumed that the alloy is in the $\beta$-phase during formation in the electrolytic cell. Upon cooling below the $\beta$-transus, the $\alpha$-phase will precipitate out producing the lathe structures observed in the micrographs.

A change in microstructure can be seen with varying concentrations of tantalum. With lower concentrations of tantalum (e.g. Ti-10Ta) the predominant phase appears to be $\alpha \mathrm{Ti}$ (HCP) denoted by the darker regions in Figure 3. This region appears darker in backscattered electron mode due to the lower atomic mass of titanium compared to tantalum. The brighter, less predominant phase is presumed to be beta $\mathrm{Ti}$ (BCC). As the tantalum content is increased, the proportion of the darker $(\alpha)$ phase decreases and the proportion of the brighter $(\beta)$ phase increase, shown in Figures 3 a-i. 


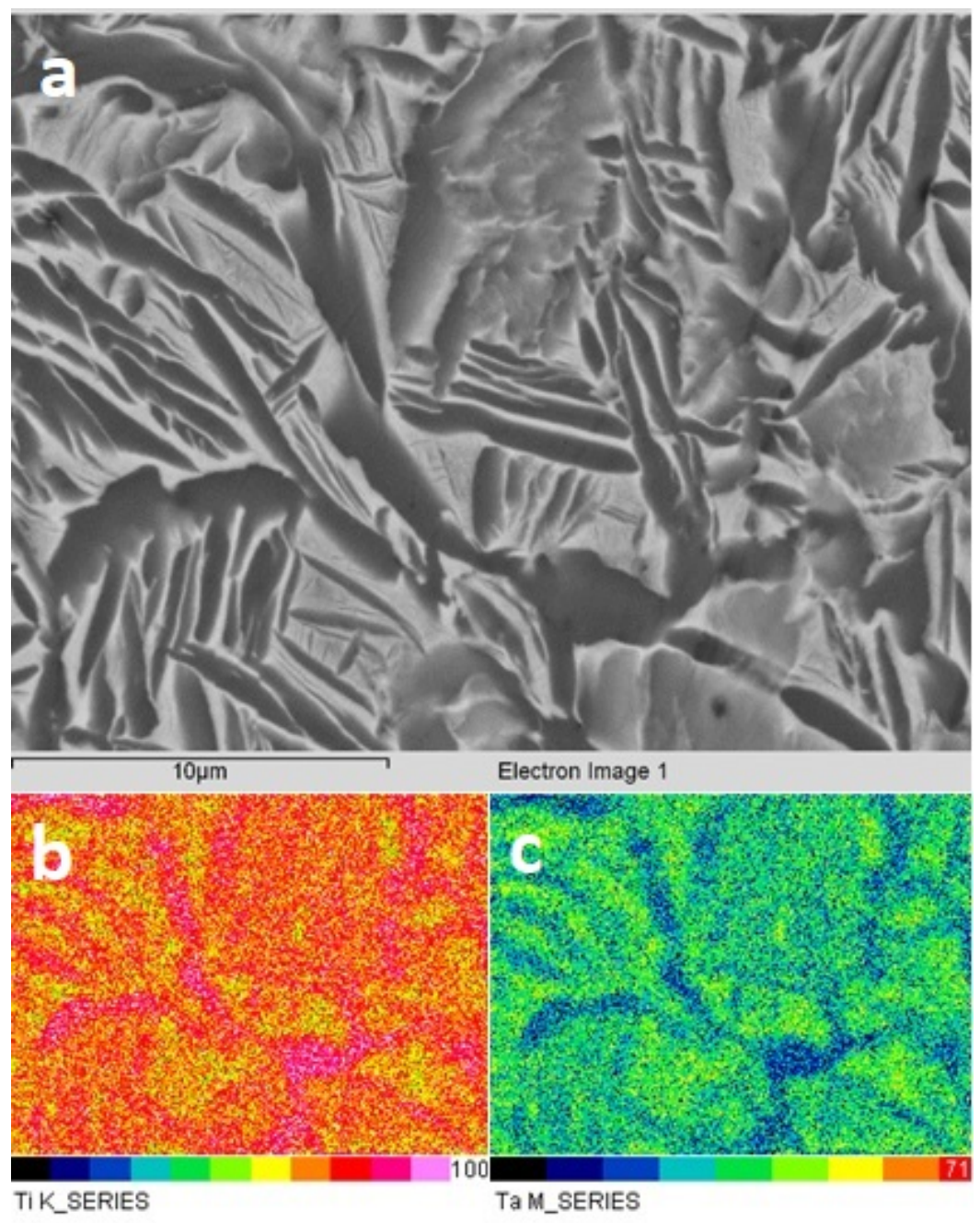

Figure 5 EDS micrograph showing b) Ti and c) Ta concentrations in Ti-Ta30wt\% alloy. Scale bar refers to Figure a). 

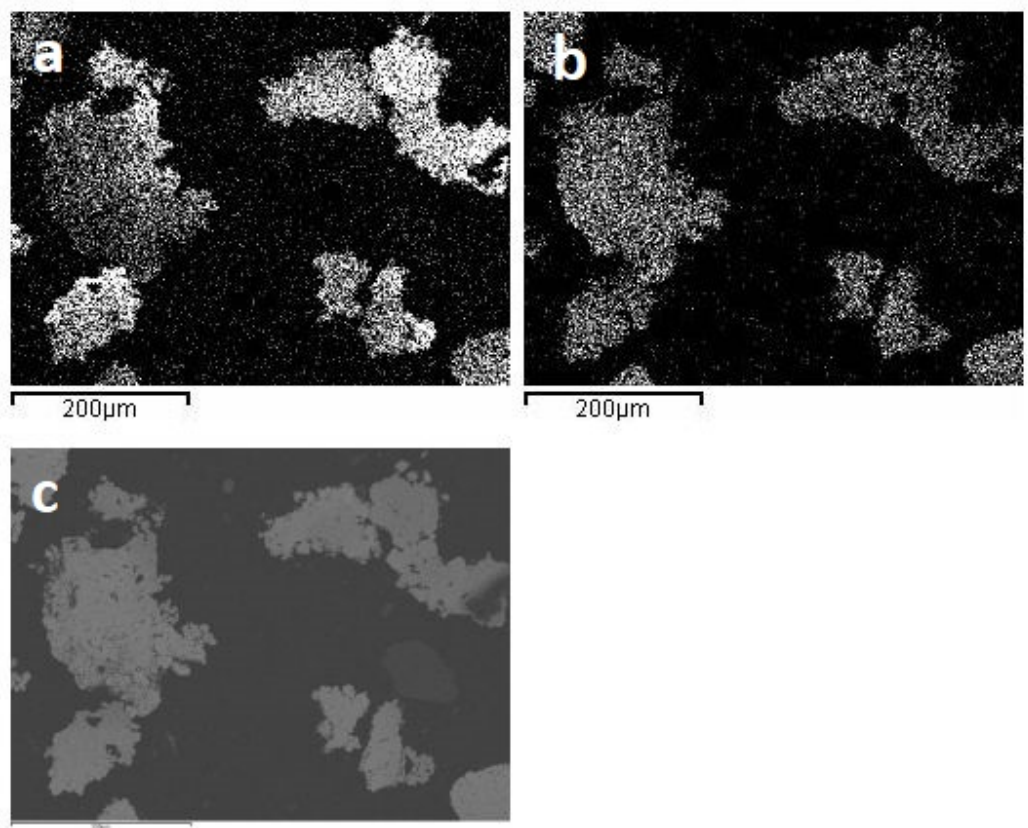

Figure 6 EDS elemental map showing the distribution of Ti and Ta in a Ti-70Ta alloy powder a) Ti distribution,

b) Ta distribution, c) electron backscattered image

Within particles containing two phases (alloys with less than $50 \mathrm{wt} \%$ tantalum), EDS analysis (Figure 5) shows a higher concentration of tantalum in the beta matrix compared to the a precipitates owing to tantalum's low solubility in a titanium. Analysis by EDS shows fairly even distribution of titanium and tantalum within each particle of powder for majority beta alloys (alloys greater than or equal to $50 \mathrm{wt} \%$ tantalum), as shown in Figure 6. There does appear to be a slight difference in tantalum and titanium concentrations between different particles but the variation does not seem too large and could be due to small scale mixing methods, larger scale mixing should overcome this. Further investigations are needed to ascertain the homogeneity of alloys upon consolidation of the metal powders. 


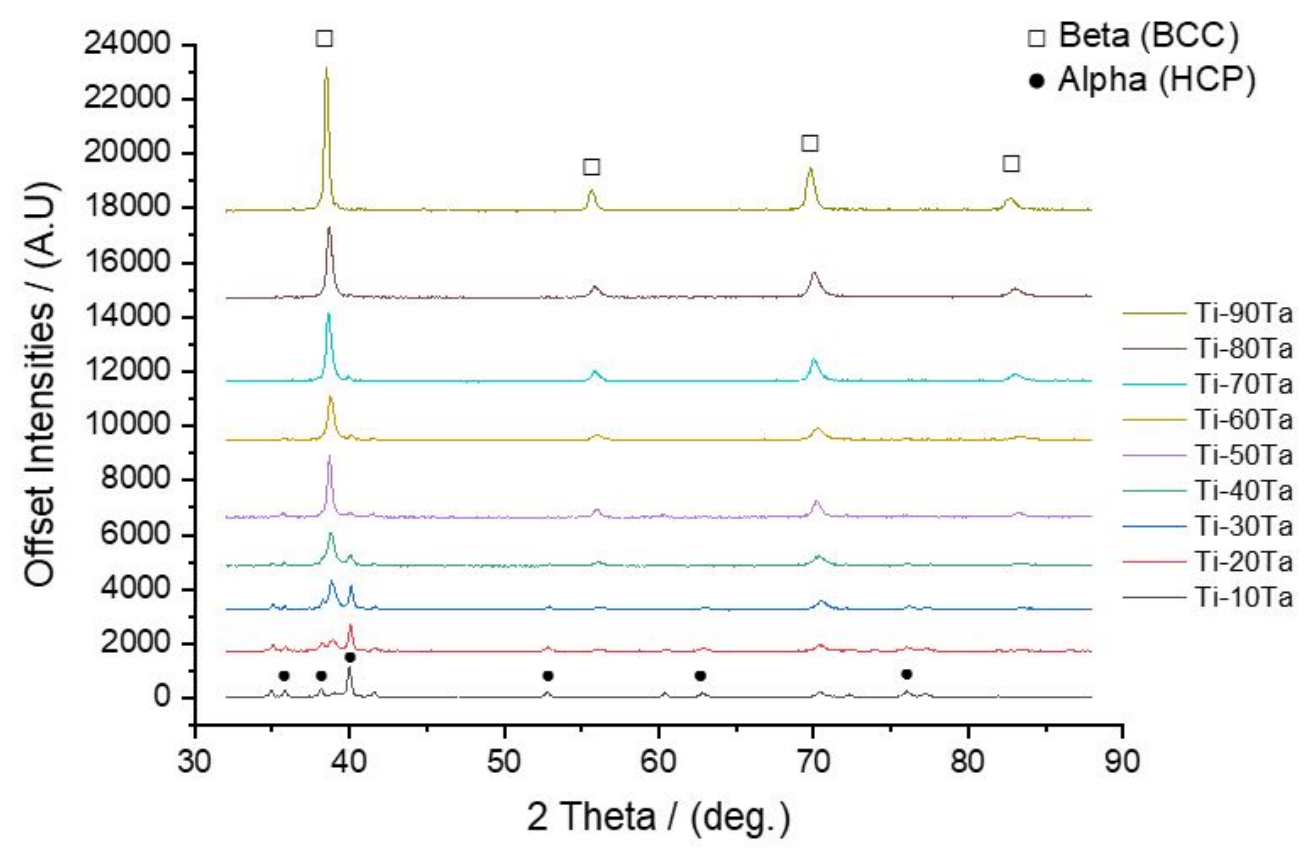

Figure 7 Powder XRD traces of Ti-Ta alloys

XRD analysis confirms the existence of both a (HCP) $\beta$ (BCC) phases in alloys with lower tantalum concentrations. There is a general increase in the proportion of BCC phase and a decrease of the HCP phase with increasing tantalum content. This is concordant with the SEM phase analysis. The aphase is undetectable by around 50wt\% Ta content, leaving a single BCC $\beta$-phase.

Table 2 Oxygen contents of Ti-Ta metal powders, determined by gas fusion analysis.

\begin{tabular}{cc}
\hline Ta Content wt\% & Oxygen / ppm \\
\hline 10 & 2703 \\
20 & 2084 \\
30 & 2564 \\
40 & 1003 \\
50 & 1108 \\
60 & 613 \\
70 & 2075 \\
80 & 1494 \\
90 & 1932 \\
\hline
\end{tabular}


Oxygen content analysis shows promising results of less than $3000 \mathrm{ppm}$ for all samples with oxygen concentrations as low as 613 ppm for Ti-60Ta alloy.

\section{Conclusions}

A range of titanium-tantalum alloys have been successfully synthesised by the electrolytic reduction of mixed oxides $\left(\mathrm{Ta}_{2} \mathrm{O}_{5} / \mathrm{TiO}_{2}\right)$ using the Metalysis-FFC process. Alloy powders exhibited a two-phase microstructure $(\alpha+\beta)$ at lower tantalum concentrations with decreasing amounts of the $\alpha$-phase (HCP) with increasing tantalum content, leading to a single $\beta$-phase (BCC) at concentrations higher than 50 $\mathrm{wt} \% \mathrm{Ta}$.

The distribution of titanium and tantalum seems fairly uniform throughout the alloy powders, larger scale mixing of oxides should improve homogeneity further. The Metalysis-FFC process could therefore be a promising method for producing titanium-tantalum alloys for use in high temperature environments such as those found in the plasma facing components in nuclear fusion reactors. It also opens the door to producing other titanium alloys, which were previously thought to be too costly or difficult to make by conventional manufacturing processes.

\section{Acknowledgements}

The authors would like to thank Metalysis and EPSRC grant EP/L016273 Centre for Doctoral training in Advanced Metallic Systems for supporting this research.

\section{$\underline{\text { References }}$}

[1] T. E. Tietz and J. W. Wilson, Behavior and properties of refractory metals: Stanford University Press, 1965.

[2] J. C. Dibbern, "Interdiffusivity in Titanium-Tantalum Alloys Processed at 1473 K," Bachelor of Science, Materials Science and Engineering, Massachusetts Institute of Technology, 2007.

[3] B. Gortikov, "Effects of processing on microstructure and properties of Ti-Ta Alloys," Massachusetts Institute of Technology, 2008.

[4] Claux, B., Serp, J. and Fouletier, J., 2011. Electrochemical reduction of cerium oxide into metal. Electrochimica Acta, 56(7), pp.2771-2780. 
[5] Gordo, E., Chen, G.Z. and Fray, D.J., 2004. Toward optimisation of electrolytic reduction of solid chromium oxide to chromium powder in molten chloride salts. Electrochimica Acta, 49(13), pp.2195-2208.

[6] Martinez, A.M., Osen, K.S., Gudbrandsen, H., Sommerseth, C., Wang, Z. and Darell, O., 2018, March. Direct method for producing scandium metal and scandium-aluminium intermetallic compounds from the oxides. In TMS Annual Meeting \& Exhibition (pp. 15591564). Springer, Cham.

[7] R. Barnett, K. T. Kilby, and D. J. Fray, "Reduction of tantalum pentoxide using graphite and tin-oxide-based anodes via the FFC-Cambridge process," Metallurgical and materials transactions B, vol. 40, pp. 150-157, 2009.

[8] Q.-s. Song, Q. Xu, X. Kang, J.-h. Du, and Z.-p. Xi, "Mechanistic insight of electrochemical reduction of $\mathrm{Ta} 2 \mathrm{O} 5$ to tantalum in a eutectic $\mathrm{CaCl} 2-\mathrm{NaCl}$ molten salt," Journal of Alloys and Compounds, vol. 490, pp. 241-246, 2010.

[9] C. Schwandt and D. Fray, "Determination of the kinetic pathway in the electrochemical reduction of titanium dioxide in molten calcium chloride," Electrochimica Acta, vol. 51, pp. 66-76, 2005.

[10] G. Z. Chen, D. J. Fray, and T. W. Farthing, "Direct electrochemical reduction of titanium dioxide to titanium in molten calcium chloride," Nature, vol. 407, pp. 361-364, 2000.

[11] L. Benson, I. Mellor, and M. Jackson, "Direct reduction of synthetic rutile using the FFC process to produce low-cost novel titanium alloys," Journal of Materials Science, vol. 51, pp. 4250-4261, 2016. 